\title{
Chemical Analysis on Two Traditional Decoctions for Diabetes Mellitus
}

\author{
Hewageegana HGSP ${ }^{1 *}$, Hewageegana $\mathrm{AU}^{2}$ and Arawwawala LDAM${ }^{3}$ \\ ${ }^{1}$ Department of Kayachikitsa, University of Colombo, Sri Lanka \\ ${ }^{2}$ Faculty of Science, University of Colombo, Sri Lanka \\ ${ }^{3}$ Industrial Technology Institute, Bauddhaloka Mawatha, Sri Lanka
}

*Corresponding author: Dr. H.G.S.P. Hewageegana, Department of Kayachikitsa, Institute of Indigenous Medicine, University of Colombo, Sri Lanka, Email: sujathahgsp@yahoo.com

\section{Research Article}

Volume 4 Issue 2

Received Date: June 14, 2020

Published Date: June 29, 2020

DOI: $10.23880 /$ jonam-16000249

\section{Abstract}

Diabetes Mellitus (DM) is a multifactorial disease involves major changes in both physical and psychosocial dimension of each patient. DM is two types; type $1 \mathrm{DM}$ and type $2 \mathrm{DM}$. Type $2 \mathrm{DM}$ is more common in the world. In the present study, an attempt was taken to evaluate (a) phytochemicals and (b) antioxidant potential of two traditional decoctions which are given to DM patients in Sri Lanka. Phytochemical screening was conducted using standard procedures and Thin Layer Chromatography fingerprint was developed using dichloromethane: ethyl acetate in a ratio of 4:1 (v/v) as the mobile phase. Results revealed that phytochemicals such as phenols, flavonoids, tannins, alkaloids, saponins, steroids and terpenoids are present in two traditional decoctions. The total polyphenolic and flavonoid contents in traditional decoction 2 (total phenols: $236.0 \pm 1.6 \mathrm{mg}$ gallic acid equivalents/g of extract; total flavonoids: $53.8 \pm 0.8 \mathrm{mg}$ quercetin/g of extract respectively) was higher than that of traditional decoction 1(total phenols: $176.5 \pm 2.1 \mathrm{mg}$ gallic acid equivalents/g of extract; total flavonoids: $41.2 \pm 1.2 \mathrm{mg}$ quercetin/g of extract respectively). In addition, IC50 value is lesser $(6.40 \pm 0.60 \mu \mathrm{g} / \mathrm{ml})$ in traditional decoction 2 for DPPH assay, compared to that of traditional decoction $1(10.52 \pm 0.35 \mu \mathrm{g} / \mathrm{ml})$. In conclusion, In vitro studies suggest that traditional decoction 2 is better than that of traditional decoction 1 in terms of antioxidant activity. Further, this can be confirmed by conducting a clinical trial in between two decoctions.

Keywords: Antioxidants; Diabetes Mellitus; Phytochemicals; Traditional Decoctions

\section{Introduction}

Type 2 Diabetes Mellitus (T2DM) is a chronic, progressive, metabolic condition, chiefly characterized by hyperglycemia due to endocrine dysfunction. This is an epidemic, affecting people globally as lifestyle modifications. Most important insulin disturbance affects to the muscles, liver and adipose tissue. Autoimmune processes, virus infections and genetic factors have been discussed as possible causes of diabetes, but the etiology of the disease is so far not settled [1,2]. Even in properly treated cases, diabetes mellitus (DM) is accompanied by number of complications and the severity increases with the duration of the disease and the degree of metabolic disorders. The clinical symptoms and signs are most often to be found in eyes, kidneys, heart and lower extremities. The chronic metabolic imbalance associated with this disease puts patients at high risk for long-term macro- and microvascular complications, which if not provided with high quality care, lead to frequent hospitalization and complications, including elevated risk for cardiovascular diseases [3]. DM is also associated with symptoms such as polyuria, fatigue, weight loss, delayed wound healing, blurred vision, increment of glucose level in urine, etc [4]. Glucose level fluctuations in the blood also responsible for the occurrence and development of diabetes complications [5]. T2DM is rapidly growing health concern in 
both developed and developing countries. According to the World Health Organization (WHO), in 2011, approximately 364 million people globally suffer from diabetes (DM), with projections that DM-related deaths will double from 2005 to 2030 [6]. To achieve good metabolic control in diabetes and keep long term, a combination of changes in lifestyle and pharmacological treatment is necessary.
Ayurveda is the major traditional system practiced in Sri Lanka and basically relies on medicinal plants. Many traditional recipes have been using to treat DM in Sri Lanka and most of them are documented in Ayurvedic texts such as "Talpate Piliyam" [7]. In the present study, an attempt was taken to assess the quality and antioxidant potential of two traditional decoctions (Table 1) given to T2DM patients.

\begin{tabular}{|c|c|c|}
\hline Botanical Name & Used Plant Part & Family of the Plant \\
\hline \multicolumn{3}{|c|}{ Traditional Decoction 1} \\
\hline Steychnos potatorum L.f & seed & Combretaceae \\
\hline Terminalia arjuna Wight \& Arn. & dried stem bark & Combretaceae \\
\hline Syzygium cumini L. & dried stem bark & Myrtaceae \\
\hline Terminalia chebula Retz. & fruit & Combretaceae \\
\hline Terminalia bellerica Roxb & fruit & Combretaceae \\
\hline Phyllanthus emblica L. & fruit & Euphorbiaceae \\
\hline Cassia auriculate L. & dried stem bark & Fabaceae \\
\hline Cedrus deodara G Don. & dried stem & Pinaceae \\
\hline Acacia catechu (L.F) Willd & dried stem & Leguminosae \\
\hline \multicolumn{3}{|c|}{ Traditional Decoction 2} \\
\hline Coscinium fenestratum Gaertn. & stem & Menispermaceae \\
\hline Curcuma longa L. & rhizome & Zingiberaceae \\
\hline Terminalia chebula Retz. & fruit & Combretaceae \\
\hline Terminalia bellerica Roxb & fruit & Combretaceae \\
\hline Phyllanthus emblica L. & fruit & Euphorbiaceae \\
\hline Cyperus rotundus $\mathrm{L}$. & rhizome & Cypereceae \\
\hline Cassia auriculata L. & dried stem, bark, flowers, leaves, root, seeds & Fabaceae \\
\hline
\end{tabular}

Table 1: Part of the plants in Traditional decoction1 and Traditional decoction 2.

\section{Materials and Methods}

\section{Collecting of plant material}

All the necessary parts of the plants were purchased from local market and authenticated by a Scientist, Bandaranayake Memorial Ayurvedic Research Institute, Sri Lanka.

\section{Preparing Procedure of the Decoctions and Freeze Dried Powders}

All plant ingredients were rinsed under running water to remove impurities such as dirt, stones and residue. Ingredients of each decoction were added to an earthen pot. A volume of $1920 \mathrm{ml}$ water was added and it was reduced into $240 \mathrm{ml}$ using mild flame about two hours. Then filtered and filtrate was subjected to free drying at $-40^{\circ} \mathrm{C}$. Freeze dried samples were labeled as "Traditional Decoction 1" and
“Traditional Decoction 2" kept in the refrigerator at $4{ }^{\circ} \mathrm{C}$.

\section{Phytochemical Screening}

Each freeze dried powder (5g) was added to $20 \mathrm{ml}$ of distilled water and subjected for phytochemical screening $[8,9]$ as follows:

\section{Test for Phenols}

- $\quad$ Ferric chloride $(1 \mathrm{ml})$ was added to $3 \mathrm{ml}$ of the extract in a test tube and mixed well. Appearance of a blue/green colour indicated the presence of phenolics.

\section{Test for Flavonoids}

- A volume of $1 \mathrm{ml}$ extract was added to $3 \mathrm{ml}$ of dilute ammonia solution, followed by the addition of concentrated $\mathrm{H}_{2} \mathrm{SO}_{4}$. Appearance of yellow colour indicates the presence of flavonoids. 


\section{Journal of Natural \& Ayurvedic Medicine}

- A volume of $\sim 2 \mathrm{ml}$ of extract was heated with $10 \mathrm{ml}$ of ethyl acetate over a steam bath filter. To $4 \mathrm{ml}$ of the filtrate, $1 \mathrm{ml}$ of ammonia solution was added and shaken vigorously. Yellow color indicated the presence of flavonoids.

\section{Test for Tannins}

- A volume of $\sim 2 \mathrm{ml}$ of extract was dissolved in $10 \mathrm{ml}$ distilled water and filtered. A volume of $2 \mathrm{ml}$ of $\mathrm{FeCl}_{3}$ was added to $2 \mathrm{ml}$ of the filtrate. Blue black precipitate indicated the presence of tannins.

- Vanillin in ethyl alcohol $(0.5 \mathrm{ml})$ and concentrated $\mathrm{HCl}$ $(0.5 \mathrm{ml})$ were added to the extract $(3 \mathrm{ml})$ in a test tube and mixed well. Red colour indicates the presence of tannins.

- A volume of $0.5 \mathrm{ml}$ was added to $1 \mathrm{ml}$ of extract. Fluorescent yellow precipitate indicates presence of tannins.

\section{Test for Alkaloids}

- A volume of $\sim 2 \mathrm{ml}$ extract was dissolved in $10 \mathrm{ml}$ of methanol and filtered. Mayor's reagent (6 drops) was added to the $2 \mathrm{ml}$ of the filtrate. Creamish, brownish red or orange precipitate indicates presence of alkaloids.

- Picric acid $(0.5 \mathrm{ml})$ was added to the extract $(3 \mathrm{ml})$ in a test tube and mixed well. Yellow crystalline precipitate indicates the presence of alkaloids.

- A volume of $0.5 \mathrm{ml}$ tannic acid was added to $1 \mathrm{ml}$ of the extract. Yellow crystalline precipitate indicates the presence of alkaloids.

\section{Test for Saponins}

- Distilled water $(5.0 \mathrm{ml})$ was mixed with the extract (10 $\mathrm{ml}$ ) in a test tube and mixed vigorously. Appearance of stable foam shows the presence of saponins.

\section{Test for Steroids}

- A volume of $2 \mathrm{ml}$ of $\mathrm{H}_{2} \mathrm{SO}_{4}$ was added to $2 \mathrm{ml}$ of acetic anhydride and $1 \mathrm{ml}$ of extract. A colour change from violet to blue/green indicates the presence of steroids.

\section{Test for Terpenoids}

- A volume of $2 \mathrm{ml}$ of extract was mixed with $1 \mathrm{ml}$ of chloroform. A volume of $2 \mathrm{ml}$ of concentrated $\mathrm{H}_{2} \mathrm{SO}_{4}$ was added along the sided of the test tube to form a layer. A reddish brown indicates the presence of terpenoids.

- A volume of $0.5 \mathrm{ml}$ vanillin ethanol was added to $1 \mathrm{ml}$ extract. Few drops of concentrated $\mathrm{H}_{2} \mathrm{SO}_{4}$ was added. A red color indicates presence of monoterpenes.

- Few drops of concentrated $\mathrm{H}_{2} \mathrm{SO}_{4}$ were added to $1 \mathrm{ml}$ extract. Brown green, red or blue indicates the presence of sesquiterpenes.

\section{Development of Thin Layer Chromatography (TLC)}

Each decoction $(50 \mathrm{ml})$ was diluted with distilled water $(50 \mathrm{ml})$ and added to a separating funnel containing $50 \mathrm{ml}$ of dichloromethane. Mixed well and left for separation. Dichloromethane layer was collected to a beaker and repeated the same procedure thrice. Then dichloromethane extract was subjected to concentrate using a rotavapor, until the volume was reduced up to $10 \mathrm{ml}$. TLC fingerprints were developed for both "Traditional Decoction 1" and "Traditional Decoction 2" using dichloromethane: ethyl acetate in a ratio of $4: 1(\mathrm{v} / \mathrm{v})$ as the mobile phase.

\section{Quantification of Total Polyphenol Content and Total Flavonoid Content}

Total polyphenol content was calculated using the calibration curve of gallic acid and the results were expressed in terms of mg gallic acid equivalents/g of extract [10]. The flavonoid content was calculated using the calibration curve of quercetin and results were expressed in terms of $\mathrm{mg}$ quercetin equivalent/g of extract [11].

\section{DPPH Free Radical Scavenging Activity}

The DPPH free radical scavenging assay was performed according to the method described by Blois (1958) with some modifications in 96-well micro-plates [12]. Five different concentrations of Trolox $(2.5,5,10,20,30 \mu \mathrm{g} / \mathrm{ml})$ were used to construct the standard curve. Results were expressed as IC50; $\mu \mathrm{g} / \mathrm{ml}$.

\section{Results and Discussion}

The demand of the herbal drugs is increasing worldwide generally and particularly in the developed countries but one of the drawbacks in its acceptability is lacking of proper standardization procedure. Purity, safety, potency and efficacy are four main pillars of herbal drug standardization. Many efforts have been taken to standardize herbal medicinal preparations- Vipadikahara Grita Taila [13] and decoctions $[14,15]$ in Sri Lanka. In the present study two traditional decoctions were evaluated for phytochemicals in terms of qualitative and quantitative analysis and developed TLC fingerprints. Results revealed that phytochemicalsphenols, flavonoids, tannins, alkaloids, saponins, steroids and terpenoids are present in both traditional decoctions. It is well documented that phytochemicals play a major role in the control of DM $[16,17]$. Therefore, presence of phenols, flavonoids, tannins, alkaloids, saponins, steroids and terpenoids may responsible in control of DM. TLC is one of the basic, cheap and simple analytical techniques to standardize herbal drugs. Individual compound/mixture 
of compounds in a TLC fingerprint profile appear as spots and each spot has a retention factor (Rf) which is equal to the distance migrated over the total distance covered by the solvent. In the present study also Rf values were recorded for both decoctions (Table 2).

\begin{tabular}{|c|c|c|}
\hline Wave Length & $\begin{array}{c}\text { Retention factor }\left(\mathbf{R}_{\mathbf{f}}\right) \text { values Traditional } \\
\text { Decoction 1 }\end{array}$ & $\begin{array}{c}\text { Retention factor }\left(\mathbf{R}_{\mathbf{f}} \text { ) values Traditional }\right. \\
\text { Decoction 2 }\end{array}$ \\
\hline \multirow{4}{*}{$366 \mathrm{~nm}$} & 0.12 & 0.32 \\
\cline { 2 - 3 } & 0.45 & 0.4 \\
\cline { 2 - 3 } & 0.64 & 0.48 \\
\cline { 2 - 3 } & 0.76 & 0.58 \\
\cline { 2 - 3 } & 0.89 & 0.67 \\
\cline { 2 - 3 } & & 0.75 \\
\cline { 2 - 3 } & & 0.9 \\
\hline \multirow{5}{*}{$254 \mathrm{~nm}$} & 0.08 & 0.11 \\
\cline { 2 - 3 } & 0.31 & 0.18 \\
\cline { 2 - 3 } & 0.36 & 0.32 \\
\cline { 2 - 3 } & 0.45 & 0.4 \\
\cline { 2 - 3 } & 0.84 & 0.67 \\
\hline
\end{tabular}

Table 2: Retention factor $\left(\mathrm{R}_{\mathrm{f}}\right)$ values in the Thin Layer Chromatography fingerprints of Traditional Decoction 1" and “Traditional Decoction 2.

Antioxidant potential was evaluated for both decoctions using DPPH assay, total polyphenol content and total flavonoid content. An antioxidant capacity of each decoction was expressed in terms of $\mathrm{IC}_{50}$ value and low $\mathrm{IC}_{50}$ value corresponds to a high antioxidant capacity. DPPH is a stable radical which gives a dark purple color at $517 \mathrm{~nm}$. When DPPH radical react with an antioxidant, its purple colour is disappeared and gives pale yellow colour at 517 $\mathrm{nm}$ [18]. The total polyphenolic and flavonoid contents in traditional decoction 2 (total phenols: $236.0 \pm 1.6 \mathrm{mg}$ gallic acid equivalents/g of extract; total falvonoids: $53.8 \pm 0.8 \mathrm{mg}$ quercetin/g of extract respectively) was higher than that of traditional decoction 1(total phenols: $176.5 \pm 2.1 \mathrm{mg}$ gallic acid equivalents/g of extract; total falvonoids: $41.2 \pm 1.2 \mathrm{mg}$ quercetin/g of extract respectively). In addition, IC $_{50}$ value is lesser $(6.40 \pm 0.60 \mu \mathrm{g} / \mathrm{ml})$ in traditional decoction 2 for DPPH assay, compared to that of traditional decoction 1 $(10.52 \pm 0.35 \mu \mathrm{g} / \mathrm{ml})$. High content of phenols and flavonoids present in traditional decoction 2 may contribute for better scavenging ability of DPPH radicals. Four medicinal plants ( $T$. chebula, T. bellerica, $P$. emblica and $C$. auriculata) are common to both decoctions and difference in antioxidant activity may be due the other plant/s present in decoction 1 and 2 or synergistic activity.

In conclusion, in the present study, phytochemicals and antioxidant potential was evaluated for two traditional decoctions used for DM. In vitro studies suggest that traditional decoction 2 is the best in terms of antioxidant activity. Further, this can be confirmed by conducting a clinical trial in between two decoctions.

\section{References}

1. Podoisky S (1980) Clinical diabetes: modern management. New York: Appleton-Century-Crofls.

2. Rifkin H, Raskin P (1981) Diabetes mellitus. Vol V, Bowie, Maryland: Robert J. Brady Company.

3. (2015) Internal Clinical Guidelines Team. Type 2 Diabetes in Adults: Management. London: National Institute for Health and Care Excellence, pp: 28.

4. Moradi B, Abbaszadeh S, Shahsavar S, lizadeh M, Beyranvand F (2018) Biomedical Research and Therapy. The most useful medicinal herbs to treat diabetes 5: 2538-2551.

5. Muggeo M, Zoppini G, Bonora E, Brun E, Bonadonna RC, et al. (2000) Fasting plasma glucose variability predicts 10-year survival of type 2 diabetes patients: the Verona Diabetes Study. Diabetes Care 23(1): 45-50.

6. World Health Organization (2011), Diabetes: Key Facts, World Health Organization, Geneva, Switzerland. 
7. Talpate Piliyam (1993) Department of Ayurveda, Deepani press, Sri Lanka.

8. Karunakaran R, Thabrew MI, Thammitiyagodage GM, Galhena BP, Arawwawala LDAM (2017) The gastroprotective effect of ethyl acetate fraction of hot water extract of Trichosanthes cucumerina Linn and its underlying mechanisms. BMC Complementary and Alternative Medicine 17(1): 312.

9. Dahanayake JM, Perera PK, Galappatty PG, Perera HDSM, Arawwawala LDAM (2019) Comparative Phytochemical analysis and antioxidant activities of Tamalakyadi decoction with its modified dosage forms. Evidence Based Complementary and Alternative Medicine 2019: 9.

10. Singleton VL, Orthofer R, Lamuela-Raventos RM (1999) Analysis of total phenols and other oxidation substrates and antioxidants by means of Folin-Ciocalteu reagent. Methods in Enzymology 299: 152-178.

11. Meda A, Lamien CE, Romito M, Millogo J, Nacoulma OG (2005) Determination of the total phenolic, flavonoid and proline contents in Burkina Fasan honey, as well as their radical scavenging activity. Food Chemistry 91(3): 571-577.

12. Blois MS (1958) Antioxidant determinations by the use of a stable free radical. Nature 181: 1199-1200.
13. Hewageegana HGSP, Arawwawala LDAM, Fernando PIPK, Dhammarathana I, Ariyawansa HAS, et al. (2013) Standardization of Vipadikahara Grita Taila: An Ayurvedia medicated oil for common skin diseases. Unique Journal of Ayurveda Herbal Medicine 1(1): 4851.

14. Hewageegana HGSP, Arawwawala LDAM (2013) Phytochemical and Antioxidant activity of Traditional decoction Use for Type2 Diabetes Mellitus. Universal Journal of Pharmacy 2: 134-137.

15. Wickramaarachchi WMD, Wakkumbura HP, Arawwawala LDAM, Rajapaksa RPVJ (2016) Standardization of the formula of Panchamuli Laghu Draksha Kasaya: A traditional herbal medicine. World Journal of Pharmacy and Pharmaceutical Sciences 5: 172-179.

16. Gaikwad SB, Mohan GK, Rani MS (2014) Phytochemicals for diabetes management. Pharmaceutical Crops. 4: 1128.

17. Teoh SL, Das S (2018) Phytochemicals and their effective role in the treatment of diabetes mellitus: A short review 17: 1111-1128.

18. Pisoschi AM, Negulescu GP (2011) Methods for total antioxidant activity determination: A review. Biochem Anal Biochem 1: 106-112. 